\title{
Estimating Biomass from the Cover of Gelidiella acerosa along the Coasts of Eastern Philippines ${ }^{1}$
}

\author{
Rene N. Rollon ${ }^{\mathrm{a}, \mathrm{b} *}$, Maricar S. Samson ${ }^{\mathrm{b}}$, Michael Y. Roleda ${ }^{\mathrm{c}, \mathrm{b}}$, Karen G. Araño ${ }^{\mathrm{b}}$, \\ Mark Windell B. Vergara ${ }^{\mathrm{b}}$ and Wilfredo Y. Licuanan ${ }^{\mathrm{c}, \mathrm{b}}$
}

\author{
a Institute of Environmental Science and Meteorology, College of Science, University of the Philippines, Diliman, Quezon \\ City 1101, The Philippines, e-mail: rnrollon@up.edu.ph \\ b The Marine Science Institute, College of Science, University of the Philippines, Diliman, Quezon City 1101, The \\ Philippines \\ c Biology Department, De La Salle University, 2401 Taft Avenue, Manila 1004, The Philippines \\ * Corresponding author
}

In three Gelidiella acerosa beds on the poorly-studied eastern coasts of the Philippines, cover and biomass of this commercially important agar-producing red alga were measured. The three selected G. acerosa beds represented low (mean cover $<5 \%$ ), medium (approximately $10 \%$ ) and high cover $(>20 \%)$ vegetation. In each of the sites, we estimated the cover of G. acerosa fronds within $10 \times 10 \mathrm{~cm}$ grids (n ranged from 33-36) in various strata. All G. acerosa fronds within each grid were harvested, cleaned of attached epiphytes and sediments, and subsequently, oven-dried at $60^{\circ} \mathrm{C}$ to constant weight. We applied regression analysis to establish empirical relationships between cover and biomass. All linear regression lines were highly significant ( $p<0.001, \mathrm{R}^{2}>0.6$ ) indicating that biomass could be confidently estimated from cover estimates: low cover $\left(\mathrm{y}=0.0171 \mathrm{x}+0.310 ; \mathrm{R}^{2}=0.67, \mathrm{p}<0.0001\right)$, medium cover $\left(\mathrm{y}=0.0363 \mathrm{x}+0.118, \mathrm{R}^{2}=0.83, \mathrm{p}<0.0001\right)$ and high cover $\left(\mathrm{y}=0.0304 \mathrm{x}+0.481, \mathrm{R}^{2}=0.80, \mathrm{p}<0.0001\right)$. Evidently though, sites with higher overall mean cover (also longer thalli) had significantly steeper regression slopes, which was most pronounced when comparing sites with the lowest $(<5 \%)$ and highest $(>20 \%)$ mean cover. Nevertheless, we subsequently projected a minimum annual yield from the known 51 ha along the eastern coasts amounting to, at a minimum, $23 \mathrm{t} \mathrm{dw} \mathrm{y}^{-1}$. Such yield may translate to approximately 68.8 million pesos (US\$ 1.38 million) in gross sales of agar.

Keywords: agarophytes; marine macrobenthic algae; natural stocks; Philippine Pacific seaboard.

\section{Introduction}

Gelidiella acerosa (Forsskaal) Feldmann et Hamel is among the most important marine algae producing high quality agar on a commercial scale (Subbaramaiah et al. 1975, Thomas et al. 1975, Armisen and Galatas 1987, Ganzon-Fortes 1994, Kapraun et al. 1994, Ganzon-Fortes 1997). This species is abundant in many areas in the Philippines (e.g., Hurtado-Ponce et al. 1992, Ganzon-Fortes 1994), including the Philippine Pacific seaboard (> $60 \%$ of the sites surveyed; Roleda et al. unpublished data), where there is a mean cover of $25 \%$ in some sites. Due to frequent rough seas and logistic constraints (e.g., lack of large research vessels and sufficient research funding), the abundance and distribution of macrobenthic algae in this region remains poorly understood.

Like many other macroalgal species, spatial and temporal resource availability of G. acerosa has been estimated usually only by cover and frequency of occurrence (sensu Saito and Atobe 1970) within sites (e.g. Rollon et al. 1992, Tiquio and Fortes 1992). Har-

\footnotetext{
$\overline{{ }^{1} \text { Submitted } 12}$ November 2002; accepted 2 July 2003
}

vesting the resource to determine natural stocks (e.g., Thomas et al. 1975, Abanil et al. 1984, GanzonFortes 1985, 1988, Fortes 1992) has seldom been used, since it is destructive and logistically more difficult. For instance, to avoid depleting the natural stock of the study area, Roleda et al. (1997) estimated in situ biomass (i.e., g per $50 \times 50 \mathrm{~cm}$ ) of the species by proportionately dividing the weight obtained from only one small grid (i.e., $10 \times 10 \mathrm{~cm}$ ) having the highest cover among a total of 25 grids. However, such an approach, though it may be highly practical, would be unrepresentative since the cover of a single grid ranges from $50-100 \%$ (see details in Saito and Atobe 1970). Moreover, harvesting may not be appropriate for temporal studies requiring repetitive measures on the same plot. In assessing the economic potential and utilization management of important resources like G. acerosa, knowledge on the spatiotemporal changes in biomass (without being destructive) is crucial.

Hence, in this paper, our general goal is to establish empirical relationships between G. acerosa cover and biomass. We performed the exercise in three $G$. acerosa beds of varying mean cover to test whether 
such empirical relationships would be dependent on overall algal abundance. We applied both categorical (sensu Saito and Atobe 1970; i.e., cover classes of $0-5$ ) and more quantitative estimation (i.e., to the nearest percentage point) of algal cover and evaluated their comparability. Since the method of Saito and Atobe (1970) is more generally followed in the literature, such a comparison would strengthen the generality of the models explored herein.

\section{Material and Methods}

From the extensive database on frequency and cover of macroalgae in 80 transect sites along the approximately 2000-km Philippine Pacific coastline (Samson et al. unpublished data), we chose three sites having different mean G. acerosa cover (Fig. 1): low (mean cover $<5 \%$ ), medium (approximately $10 \%$ ) and high $(>20 \%)$. All three sites were similarly shallow $(0-0.5 \mathrm{~m}$ below mean low water level), clear-water $\left(\mathrm{K}_{\mathrm{d}}<1 \mathrm{~m}^{-1}\right)$ and had rocky substrata. In each of the sites, the cover (to the nearest percentage point) of G. aceros $a$ within $10 \times 10 \mathrm{~cm}$ grids was estimated, with sample size ranging from 33 to 36 . Grids were chosen to represent the entire cover spectrum at the

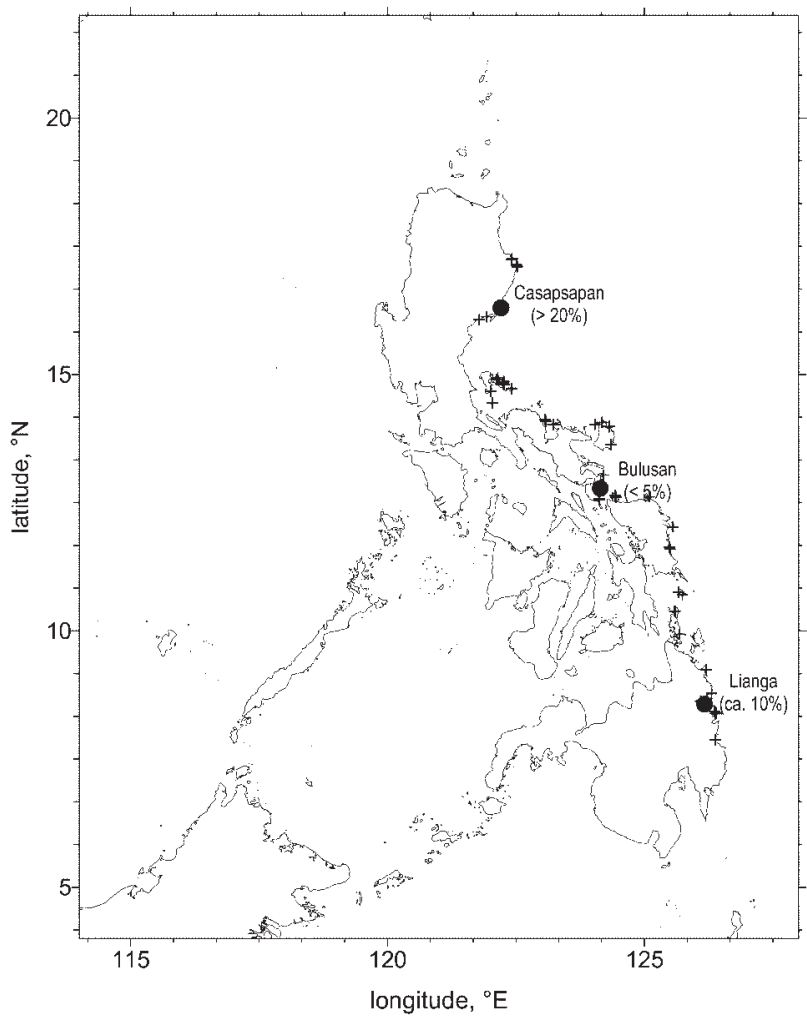

Fig. 1. The three study sites $(\bullet)$ along the coasts of eastern Philippines: Casapsapan $\left(16.32391{ }^{\circ} \mathrm{N}, 122.19267^{\circ} \mathrm{E}\right.$; high cover $)$, Bulusan $\left(12.77126^{\circ} \mathrm{N}, 124.14933^{\circ} \mathrm{E}\right.$; low cover $)$ and Lianga $\left(8.56135^{\circ} \mathrm{N}, 126.17480{ }^{\circ} \mathrm{E}\right.$; medium cover). The other 48 sites ( + ) where G. acerosa was found (Roleda et al. unpublished data) are also shown. site (e.g., 1-90\%). All G. acerosa fronds within each grid were harvested and placed in separate, pre-labelled plastic bags. In the laboratory, the G. acerosa samples were thoroughly cleaned of attached epiphytes and sediments, and oven-dried at $60{ }^{\circ} \mathrm{C}$ to constant weight.

The empirical relationships between cover and biomass in three sites were evaluated using linear regression. To further test whether there is a strong relationship to biomass regardless of the degree of cover, we also applied the regression analysis disregarding higher cover values (i.e., $>50 \%,>25 \%$ ). To test whether determining cover following the methods by Saito and Atobe (1970) would also yield similar empirical cover-biomass relationships, we took average values from three cover measurements randomly chosen from the same data set per site. For instance, three grids having quantitative in situ cover estimates of 85,45 and $10 \%$ (averaging approximately $47 \%$ ) would have corresponding Saito and Atobe cover categories of 5, 4 and 2 respectively. Consequently, the corresponding Saito and Atobe numerical cover for such grids would be $75,37.5$ and $9.375 \%$, averaging approximately $41 \%$. We continued taking sets of three random samples until all data were utilized. Correspondingly, we took means of three biomass values. Regression analysis was applied as above.

To test whether significant differences exist between regression lines within and between sites, we calculated F-statistics (see details in Vermaat and Hootsmans 1994), subsequently evaluating significance at $\mathrm{p}<0.05$.

We then applied the resulting regression models to project very crude estimates of the total standing stock and annual yield of all the 51 sites (i.e., $64 \%$ of the 80 total transect sites surveyed previously; Roleda et al. unpublished data; Fig. 1) where G. acerosa occurred, to speculate on the potential utilization of the resource. In each of these sites, frequency and cover (following Saito and Atobe 1970) of G. acerosa were previously quantified (Roleda et al. unpublished data) across 100-m lines perpendicular to the shoreline, applying a point-intercept (transect-quadrat) method.

\section{Results and Discussion}

All linear regression lines were highly significant (Table I) indicating that biomass could be confidently derived from cover estimates: low cover $(\mathrm{y}=$ $\left.0.0171 \mathrm{x}+0.310 ; \mathrm{R}^{2}=0.67, \mathrm{p}<0.0001\right)$, medium cover $\left(\mathrm{y}=0.0363 \mathrm{x}+0.118, \mathrm{R}^{2}=0.83, \mathrm{p}<0.0001\right)$ and high cover $\left(\mathrm{y}=0.0304 \mathrm{x}+0.481, \mathrm{R}^{2}=0.80, \mathrm{p}<0.0001\right)$. At worst, i.e., when mean was low $\left(\mathrm{R}^{2}=0.67\right.$, Table I), $33 \%$ of the biomass variation could not be explained by variation in cover. Within any site, no significant differences could be found between "all data" and those disregarding higher values (i.e. $<50 \%$ and 
Table I. Equations regressing cover estimates against biomass values of G. acerosa within $10 \times 10 \mathrm{~cm}$ grids.

\begin{tabular}{|c|c|c|c|c|c|c|c|}
\hline Site, cover category & Data set & $\mathrm{N}$ & Regression equation & R-square & p-value & ${ }^{2} \mathrm{~F}$ & ${ }^{3} \mathrm{~F}$ \\
\hline \multirow[t]{4}{*}{ Bulusan, low } & Cover $<25 \%$ & 17 & $\mathrm{y}=0.0226 \mathrm{x}+0.212$ & 0.45 & 0.0034 & \multirow{4}{*}{ a } & \\
\hline & Cover $<50 \%$ & 21 & $y=0.0358 x+0.042$ & 0.80 & $<0.0001$ & & \\
\hline & All data & 33 & $\mathrm{y}=0.0171 \mathrm{x}+0.310$ & 0.67 & $<0.0001$ & & \\
\hline & Randomized $^{1}$ & 11 & $y=0.0114 x+0.466$ & 0.56 & $<0.01$ & & $\mathrm{a}$ \\
\hline \multirow[t]{4}{*}{ Lianga, medium } & Cover $<25 \%$ & 23 & $\mathrm{y}=0.0481 \mathrm{x}-0.025$ & 0.68 & $<0.0001$ & \multirow{4}{*}{$\mathrm{c}$} & \\
\hline & Cover $<50 \%$ & 33 & $y=0.0485 x-0.048$ & 0.85 & $<0.0001$ & & \\
\hline & All data & 36 & $y=0.0363 x+0.118$ & 0.83 & $<0.0001$ & & \\
\hline & Randomized $^{1}$ & 12 & $\mathrm{y}=0.0270 \mathrm{x}+0.321$ & 0.55 & 0.0055 & & $a b$ \\
\hline \multirow[t]{4}{*}{ Casapsapan, high } & Cover $<25 \%$ & 21 & $\mathrm{y}=0.0405 \mathrm{x}+0.297$ & 0.59 & $<0.0001$ & \multirow{4}{*}{$\mathrm{b}$} & \\
\hline & Cover $<50 \%$ & 29 & $\mathrm{y}=0.0459 \mathrm{x}+0.231$ & 0.81 & $<0.0001$ & & \\
\hline & All data & 35 & $\mathrm{y}=0.0304 \mathrm{x}+0.481$ & 0.80 & $<0.0001$ & & \\
\hline & Randomized $^{1}$ & 12 & $\mathrm{y}=0.0331 \mathrm{x}+0.342$ & 0.86 & $<0.0001$ & & $\mathrm{~b}$ \\
\hline
\end{tabular}

At all sites, no significant differences (i.e., p > 0.05) exist between data sets having cover $<25 \%,<50 \%$ and "all data", and between "all data" and randomly chosen subset. R-square and p-values pertain to the corresponding regression equation. $\mathrm{N}=$ number of data pairs used for the regression.

${ }^{1} \mathrm{n}$ pairs of cover-biomass values averaged from three, randomly-chosen grid readings following Saito and Atobe (1970).

${ }^{2}$ F-test, comparing only "all-data" regression lines across sites: different letters indicate significant difference at $\mathrm{p}<0.05$.

${ }^{3}$ F-test, comparing only "randomized" regression lines across sites: different letters indicate significant difference at $\mathrm{p}<0.05 ; \mathrm{ab}$ is not significantly different from either $\mathrm{a}$ or $\mathrm{b}$.

Table II. Crude projection of standing stock and annual yield of G. acerosa.

\begin{tabular}{lclccc}
\hline $\begin{array}{l}\text { Mean } \\
\text { cover }\end{array}$ & $\begin{array}{l}\mathrm{N} \\
\text { sites }\end{array}$ & $\begin{array}{l}\text { Mean standing } \\
\text { stock } \pm \mathrm{SD} \\
\left(\mathrm{kg} \mathrm{ha}^{-1}\right)^{*}\end{array}$ & $\begin{array}{l}\text { Total standing } \\
\text { stock per cover } \\
\text { category }(\mathrm{kg}) * *\end{array}$ & $\begin{array}{l}\text { Annual yield, 7-month } \\
\text { regeneration period } \\
\left(\mathrm{kg} \mathrm{y}^{-1}\right)^{* * *}\end{array}$ & $\begin{array}{l}\text { Annual yield, 11-month } \\
\text { regeneration period } \\
\left(\mathrm{kg} \mathrm{y}^{-1}\right)_{* * * *}\end{array}$ \\
\hline $0-<5$ & 43 & $478 \pm 13(376 \pm 37)$ & $20535(16148)$ & $35202(27682)$ & $22401(17616)$ \\
$5-<10$ & 7 & $548 \pm 19(580 \pm 54)$ & $3835(4057)$ & $6574(6954)$ & $4183(4425)$ \\
$10-<20$ & 0 & 0 & 0 & 0 & 0 \\
$20-<25$ & 1 & $719(1076)$ & $719(1076)$ & $1232(1845)$ & $784(1174)$ \\
Total & 51 & & $25088(21281)$ & $43088(36481)$ & $27369(23215)$
\end{tabular}

Values given are estimates applying regression equations (randomized, see also Table I) from sites having low and high cover (the latter in parentheses).

* We assumed that one hectare is harvested at each of the 51 sites; this minimum 1-ha assumption was based on our large survey database (Roleda et al. unpublished data; Samson et al. unpublished data). Standard deviations (SD) represent variation between sites. ** Because, as yet, we have no information on the total area per site available for harvest, these values depict only the minimum standing stock for all sites under each cover category; the total value represents only the minimum standing stock from the known 51 ha. *** Assuming a 7-month regeneration period, an average for mid-intertidal area (though such may vary from 3.5 to 11 months; see also review by Ganzon-Fortes 1994). **** Applying the longest (11-month) regeneration period, hence reflecting the minimum annual yield.

$<25 \%)$. Also, values derived following the Saito and Atobe method did not differ significantly from "direct" estimations, although corresponding $\mathrm{R}^{2}$ values appeared lower especially in G. acerosa sites having lower cover (i.e., $\leq 10 \%$ ). Evidently though, sites with higher overall mean cover (also longer thalli) had significantly steeper regression slopes (Table I, ${ }^{2} \mathrm{~F}$ and ${ }^{3}$ F-tests), which was most pronounced when comparing sites having the lowest $(<5 \%)$ and highest (>20\%) mean cover (Table I, Fig. 2). Though the comparison between medium and high regression lines yielded significant results $\left({ }^{2} \mathrm{~F}\right.$-test, Table I), the difference in regression slopes was narrow (i.e., 0.0363 vs 0.0304 , Table I).
Applying the regression equations derived following Saito and Atobe (1970), we project very crude but conservative estimates of standing stock of all 51 sites (Table II). Regression equations derived from sites having low and high cover yielded an overall difference of about $4 \mathrm{t}$ (i.e., 25088 vs $21281 \mathrm{~kg}$ dw, Table II). Consequently, the minimum annual yield projection also differed by about $4 \mathrm{t} \mathrm{y}^{-1}$ (i.e., $27369 \mathrm{vs}$ $23215 \mathrm{~kg} \mathrm{dw} \mathrm{y}^{-1}$, Table II). Comparatively, the former equation having a higher intercept value (see Table I) yields higher biomass estimates for cover values lower than 10 .

Taking just the lower projection ( $23 \mathrm{t} \mathrm{y}^{-1}$, Table II) of the minimum annual production from the known 


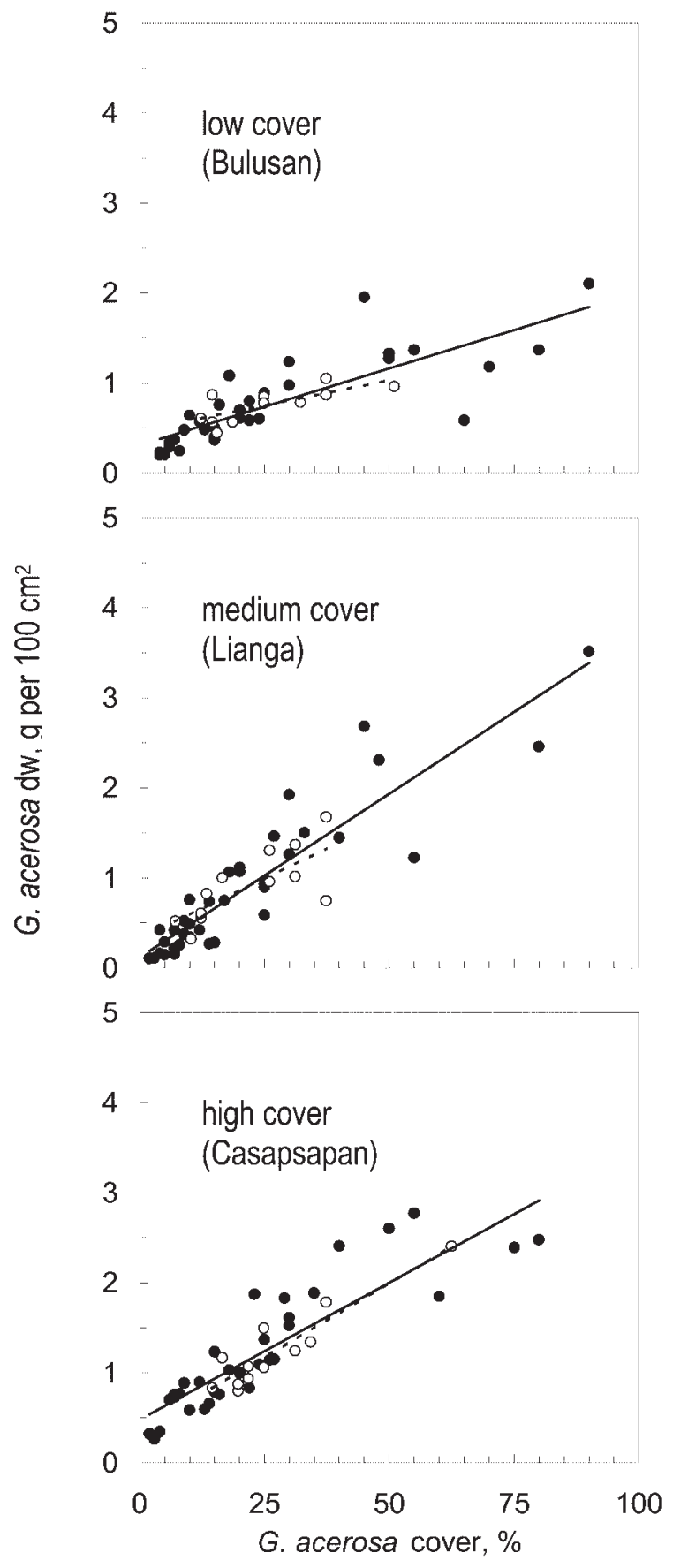

Fig. 2. The empirical relationships between G. acerosa cover and biomass in three sites along the coasts of eastern Philippines: Bulusan (low, $<5 \%$ ); Lianga (medium, approximately $10 \%$ ) and Casapsapan (high cover, > $20 \%$ ). Only regression lines for "all data" (closed circles; solid lines) and randomly chosen subsets (open circles; dotted lines) are shown. For other details, see also Table I.

51 ha, this value amounts to $58 \%$ of the national production in 1964 (Yamada 1976), and is 8 times higher than the Philippine export to Japan in 1984 (Armisen and Galatas 1987). Considering further that the agar content is $35 \%$ (though it may vary considerably; Craigie and Leigh 1978, Kapraun et al. 1994, Roleda et al. 1997, Villanueva et al. 1999), the same conserva- tive estimate of annual production may translate to $8.1 \mathrm{t} \mathrm{y}^{-1}$ of agar. Altogether, annual gross sales of $G$. acerosa worth approximately 68.8 million pesos (US\$ 1.38 million; based on 2001 herbs and spices selling price) may be derived from the known 51 ha along the Philippine Pacific seaboard. This potential annual yield increases to $36 \mathrm{t} \mathrm{y}^{-1}$ (equivalent to approximately US\$ 2 million gross sales of agar), when the average 7 -month regeneration period is applied (Table II).

Our empirical relationships, as well as subsequent crude projections, have limitations. For the cover-biomass exercises, we gathered data within the period July-September 2001. The biomass and growth during this period tend to be high (e.g., Umamaheswara Rao 1973, Thomas et al. 1975, Abanil et al. 1984, Roleda et al. 1997), although no clear seasonality has been established (see also the review by GanzonFortes 1994). For the subsequent annual yield projections, we (Roleda et al. unpublished data; Samson et al. unpublished data) sampled most of the 51 sites during the April-May period, when oceanographic cruises are best carried out. This period corresponds to a medium biomass level at the sites, and hence, our estimates would also reasonably fall in the medium range.

Another agarophyte, Laurencia flexilis Setchell producing comparatively lower quantity and quality (e.g., gel strength; Romero et al. 2000) is sometimes mistaken for G. acerosa (Trono and Ganzon-Fortes 1988). Such confusion during collection, especially by the local people, in combination with losses associated with post-harvest processing (sun-drying, pounding, bleaching, etc.) may be substantial and hence reduce the crude projection of minimum annual yield (Table II). However, such projections were based on a very conservative assumption that, per site, there exists only a 1 -ha area (i.e., $100 \times 100 \mathrm{~m}$, in view of the 100-m point-intercept measurements; Roleda et al. unpublished data) where G. acerosa could be found. Hence, such possible loss terms may be substantially offset. The economic potential of the projected gross sales also largely depends on how far the industry could minimize cost associated with agar production including efficient and sustained procurement of raw materials. We realize though that our estimate of the overall potential commercial yield is very approximate, and hence, may not be used to begin resource development without further, more quantitative studies.

In summary, this study provides regression models to derive biomass from cover estimates. Within sites, we found no significant differences between regressions models generated from Saito and Atobe (1970) procedures and those generated from the more tedious determinations of cover and biomass within small $(10 \times 10 \mathrm{~cm})$ grids. However, between sites, especially when comparing models for low and high mean cover, significant differences exist, the latter 
having steeper regression slopes. Nevertheless, we further demonstrated that G. acerosa occurs in substantial amounts along the Philippine Pacific seaboard, the minimum biomass of which may reach $>1 \mathrm{t} \mathrm{ha}^{-1}$. Based only on the 51 sites where the species occurred, the projected annual yield may amount to $23 \mathrm{t} \mathrm{y}^{-1}$, equivalent to approximately 68.8 million pesos (approximately US\$ 1.38 million) in gross sales of agar. However, utilization of $G$. acerosa on a commercial scale should be done carefully (Trono and Ganzon-Fortes 1985). Since culture of this species proved difficult (Subbaramaiah et al. 1975, Ganzon-Fortes 1994), production for the near future would most likely depend on the wild stocks. Suggestions on better harvest methods have been proposed including pruning or cutting to allow thallus regrowth (Trono and Ganzon-Fortes 1985). Still,

\section{References}

Abanil, G.J., P.C. Sia, T.T. Teru and J.C. Zarsuelo. 1984. The ecology and biology of the Gelidiella species in Mantigue Island. In: Seminar Report on the First RP-US Phycology Workshop, Manila and Dumaguete, Philippines, October 24-November 5, 1984. pp. 14-53.

Armisen, R. and F. Galatas. 1987. Production, properties and uses of agar. In: (D.J. McHugh, ed.) Production and Utilization of Products from Commercial Seaweeds. FAO Fish. Tech. Pap. pp.1-57.

Craigie, J.S. and C. Leigh. 1978. Carageenans and agars. In: (J.A. Hellebust and J.S. Craigie, eds) A Handbook of Phycological Methods - Physiological and Biochemical Methods. Cambridge University Press, New York. pp. 109-132.

Fortes, M.D. 1992. Assessment of the natural stocks of Gelidiella acerosa (Fossk.) Feld. et Hamel in Mantigue Is., Camiguin, Southern Philippines. In: (H.P. Calumpong and E.G. Meñez, eds) Proc. 2nd RP-USA Phycology Symposium/Workshop. Cebu, Philippines. pp. 247-256.

Ganzon-Fortes, E.T.1985. Reproductive Biology and Ecology of Gelidiella acerosa. Terminal Report Submitted to Philippine Council for Aquatic Marine Research and Development. Los Baños, Laguna, Philippines. pp. 25, tables, figs.

Ganzon-Fortes, E.T. 1988. Management of the Natural Stocks of the Agarophyte Gelidiella acerosa. Terminal Report Submitted to Philippine Council for Aquatic Marine Research and Development. Los Baños, Laguna, Philippines. pp. 25, tables and figs.

Ganzon-Fortes, E.T. 1994. Gelidiella. In: (I. Akatsuka, ed.) Biology of Economic Algae. SPB Academic Publishing, The Hague. pp. 149-184.

Ganzon-Fortes, E.T. 1997. Influence of tidal location on morphology, photosynthesis and pigments of the agarophyte, Gelidiella acerosa, from northern Philippines. J. Appl. Phycol. 9: 525-532.

Hurtado-Ponce, A.Q., Ma. R.J. Luhan and N.G. Guanzon Jr. 1992. Gathering of economically important seaweeds in western Visayas, Philippines. Philipp. Scientist 29:40-47.

Kapraun, F., E. Ganzon-Fortes, K.T. Bird, G. Trono and C. among the essentials to draw up a management scheme, we need a more detailed, accurate delineation of G. acerosa resources (resource maps) per site and for the entire coastline of the Philippine Pacific seaboard.

\section{Acknowledgements}

We acknowledge the research funding provided by the Department of Science and Technology - Pacific Seaboard Research and Development Program, Project 1 (Assessment of reef resources of eastern Philippines). We thank the staff of Project 1 and those of the collaborating institutions for assistance in the field. We thank the Editor-in-Chief and two anonymous referees for their constructive comments.

Breden. 1994. Karyology and agar analysis of the agarophyte Gelidiella acerosa (Forsskaal) Feldmann et Hamel from the Philippines. J. Appl. Phycol. 6: 545-550.

Roleda, M.Y., E.T. Ganzon-Fortes, N.E. Montaño and F.N. de los Reyes. 1997. Temporal variation in biomass, quantity and quality of agar from Gelidiella acerosa (Forsskaal) Feldmann et Hamel (Rhodophyta: Gelidiales) from Cape Bolinao, NW Philippines. Bot. Mar. 40: 487-495.

Rollon, R.N., J.P. Tiquio and M.D. Fortes. 1992. Variability in the estimated minimum number of quadrats yielding the asymptote value of diversity in different seaweed communities. In: (H.P. Calumpong and E.G. Meñez, eds) Proc. 2nd RP-USA Phycology Symposium/Workshop. Cebu, Philippines. pp. 209-222.

Romero, J.B., M.N.E. Montaño, F.A. Merca, R.G.O. Rumbaoa and R.D. Villanueva. 2000. Effect of sucrose on some physical properties of different Philippine agars. Philippine J. Sci. 129: 7-13.

Saito, Y. and S. Atobe. 1970. Phytosociological study of intertidal marine algae. I. Usujiri Benten-Jima, Hokkaido. Bull. Fac. Fish. Hokkaido Univ. 21:37-69.

Subbaramaiah, K., K. Rama Rao, P.C. Thomas and M.R.P Nair. 1975. Cultivation of Gelidiella acerosa. Salt Research and Industry 11:33-36.

Thomas, P.C., K. Rama Rao and K. Subbaramaiah. 1975. Periodicity in growth and production of agar of Gelidiella acerosa (Forsskaal) Feld. et Hamel. Indian J. Mar. Sci. 4: 210-212.

Tiquio, J. P. and M.D. Fortes. 1992. Distribution patterns of seaweeds in the Philippines. In: (A.C. Alcala and L.T. McManus, eds) Proc. 1st Nat. Symp. on Mar. Sci. Marine Science Institute, University of the Philippines, Diliman, Quezon City. pp.3-15.

Trono, G.C. and E.T. Ganzon-Fortes. 1985. The economic potentials of seaweeds. Philipp. Fish. Annu.: 62-68.

Trono, G.C. and E.T. Ganzon-Fortes. 1988. Philippine Seaweeds. National Bookstore, Inc., Manila. pp. 330.

Umamaheswara Rao, M.1973. Growth and reproduction of 
Gelidiella acerosa in the Palk Bay and Gulf of Mannar near Mandapan. Indian J. Fish. 20: 411-416.

Vermaat, J.E. and M.J.M. Hootsmans. 1994. Intraspecific variation in Potamogeton pectinatus L.: a controlled laboratory experiment. In: (W. van Vierssen, M.J.M Hootsmans and J.E. Vermaat, eds) Lake Veluwe, a Macrophyte-dominated System under Eutrophication Stress. Geobotany 21. Kluwer Academic Publishers, Dordrecht. pp. 26-39.
Villanueva, R.D., N.E. Montaño, J.B. Romero, A.K. Alinganga and E.P. Enriquez. 1999. Seasonal variations in the yield, gelling properties, and chemical composition of agars from Gracilaria eucheumoides and Gelidiella acerosa (Rhodophyta) from the Philippines. Bot. Mar. 42: $175-182$.

Yamada, N. 1976. Current status and future prospects for harvesting and resource management of agarophytes in Japan. Fish. Res. Bd. Can. 33:1024-1030. 